2 Johnson MK, Smith RP, Morrison D, et al. Large lung bullae in marijuana smokers. Thorax 2000; 55: 340-342.

3 Baris YI, Tan E, Kalyoncu F, et al. Digital clubbing in hashish addicts. Chest 1990; 98: 1545-1546.

4 Atkinson S, Fox SB. Vascular endothelial growth factor (VEGF)-A and platelet-derived growth factor (PDGF) play a central role in the pathogenesis of digital clubbing. J Pathol 2004; 203: 721-728.

5 Morris RR. Human pulmonary histopathological changes from marijuana smoking. J Forensic Sci 1985; 30: 345-349.

DOI: $10.1183 / 09031936.00150907$

\title{
Environmental temperature and relative humidity influence exhaled breath condensate $\mathrm{pH}$
}

\section{To the Editors:}

Exhaled breath condensate (EBC) is used to obtain information about the composition of airway surface lining fluid [1]. Acidification of EBC has been reported in different inflammatory airway diseases [2]. Interpretation of data is compromised by the fact that condensate $\mathrm{pH}$ shows day-to-day variability, even in healthy subjects [3]. Coating of condensing surfaces [4] and salivary contamination of the condensate [5] have been proposed to influence exhaled biomarker levels. It was our aim to investigate whether environmental temperature and relative humidity could influence condensate $\mathrm{pH}$ and whether they could be responsible for the observed variability.

EBC was collected from 12 healthy subjects with an R-Tube condenser (Respiratory Research Inc., Charlottesville, VA, USA) before and after the forecasted arrival of three cold, humid and two warm, dry meteorological fronts. In summer, on three occasions the room temperature and relative humidity paralleled the outside conditions; in winter, on two occasions room temperature and relative humidity were maintained at $26^{\circ} \mathrm{C}$ and between $47-52 \%$.

EBC $\mathrm{pH}$ was determined using the carbon dioxide $\left(\mathrm{CO}_{2}\right)$ standardisation method, as described previously [3]. Briefly, $\mathrm{pH}$ and $\mathrm{CO}_{2}$ were measured using a blood gas analyser (ABL 520; Radiometer, Copenhagen, Denmark) five times consecutively after 1-s $\mathrm{CO}_{2}$ load to the sample between each measurement. A $\mathrm{pH}-\mathrm{CO}_{2}$ plot was created from the results. The $\mathrm{pH}$ at $5.33 \mathrm{kPa} \mathrm{CO}$ partial pressure was calculated using the logarithmic regression equity obtained from the plot.

The arrival of forecasted meteorological fronts caused a pronounced change both in temperature and relative humidity of ambient air (table 1). In summer, when the study room conditions paralleled the weather conditions outside, EBC $\mathrm{pH}$ decreased significantly with the humid, cold fronts and inversely increased with the dry, warm front. In winter, when room conditions were controlled, EBC $\mathrm{pH}$ was not affected significantly by either the humid, cold or the dry, warm fronts. The coefficient of variation of EBC $\mathrm{pH}$ was $3.0 \pm 1.3$ under uncontrolled room conditions in summer and $1.8 \pm 0.9$ under controlled temperature and relative humidity of the room in winter $(p<0.02)$. There was no correlation between $\mathrm{pH}$ and volume of condensates.

The results have two possible readings, one clinical and the other pathophysiological. From a clinical point of view the results

\begin{tabular}{|c|c|c|c|c|c|c|}
\hline \multirow{2}{*}{$\begin{array}{l}\text { TABLE } 1 \\
\text { Season }\end{array}$} & \multicolumn{6}{|c|}{$\begin{array}{l}\text { Effect of meteorological fronts on exhaled breath } \\
\text { condensate (EBC) } \mathrm{pH}\end{array}$} \\
\hline & Front & Day & $\begin{array}{c}\text { Temp. } \\
{ }^{\circ} \mathrm{C}\end{array}$ & $\mathbf{R H}$ & EBC pH & p-value \\
\hline \multirow[t]{6}{*}{ Summer } & Humid & Before & 29 & 53 & $6.11 \pm 0.18$ & 0.008 \\
\hline & & After & 18 & 74 & $5.92 \pm 0.19$ & \\
\hline & Humid & Before & 30 & 38 & $5.96 \pm 0.20$ & 0.030 \\
\hline & & After & 23 & 53 & $5.83 \pm 0.13$ & \\
\hline & Dry & Before & 23 & 40 & $5.88 \pm 0.20$ & 0.015 \\
\hline & & After & 31 & 36 & $6.02 \pm 0.16$ & \\
\hline \multirow[t]{4}{*}{ Winter } & Humid & Before & 16 & 53 & $6.00 \pm 0.15$ & NS \\
\hline & & After & 5 & 83 & $5.97 \pm 0.16$ & \\
\hline & Dry & Before & 1 & 55 & $5.98 \pm 0.24$ & NS \\
\hline & & After & 12 & 42 & $5.95 \pm 0.14$ & \\
\hline
\end{tabular}

Temperature (temp.) and relative humidity $(\mathrm{RH})$ were registered at the time of collections. Study room temperature and $\mathrm{RH}$ paralleled the outside conditions in summer and were kept at $26^{\circ} \mathrm{C}$ and between $47-52 \%$ in winter. EBC pH values are presented as mean \pm SD. NS: nonsignificant.

suggest that controlling room temperature and relative humidity should be part of standardisation of EBC collection. From a pathophysiological point of view the results are interesting as they may contribute to the explanation of catching a common cold. It is not clear why the microbes that are present continuously in the air and on the mucous membranes cause respiratory tract infections that are more likely in cold weather. Compared with the stability of blood $\mathrm{pH}$, changes $\geqslant 0.5$ may occur in the $\mathrm{pH}$ of EBC and probably, therefore, the airway surface lining fluid. A relative important change in $\mathrm{pH}$ may result in a decrease in the ciliary beat [6] or in the activity of immune cells. The deterioration in the function of the nonspecific immune barrier may allow the viruses to invade the tissues.

It is widely accepted that meteorological factors can trigger several respiratory diseases. Asthma attacks have been related to: the rupture of pollens during thunderstorms [7]; higher concentrations of sulphur dioxide, nitric oxide and carbon monoxide in the air; and lower temperature and sunshine hours [8]. Exacerbations of chronic obstructive pulmonary disease have been demonstrated to be more frequent in cold weather [9]. 
In summary, the results suggest that environmental temperature and relative humidity contribute to the variability of condensate $\mathrm{pH}$.

T. Kullmann*, I. Barta, B. Antus, M. Valyon" and I. Horváth " *Dept of Pathophysiology and ${ }^{\#}$ Clinical Laboratory, National Korányi Institute for TB and Pulmonology "Institute of Human Physiology and Clinical Experimental Research, Semmelweis University, Budapest, Hungary.

\section{STATEMENT OF INTEREST}

None declared.

\section{REFERENCES}

1 Horváth I, Hunt J, Barnes PJ. Exhaled breath condensate: methodological recommendations and unresolved questions. Eur Respir J 2005; 26: 523-548.

2 Hunt JF, Fang K, Malik R, et al. Endogenous airway acidification: implications for asthma pathophysiology. Am J Respir Crit Care Med 2000; 161: 694-699.
3 Kullmann T, Barta I, Lázár Z, et al. Exhaled breath condensate $\mathrm{pH}$ standardised for $\mathrm{CO}_{2}$ partial pressure. Eur Respir J 2007; 29: 496-501.

4 Rosias PP, Robroeks CM, Niemarkt HJ, et al. Breath condenser coatings affect measurement of biomarkers in exhaled breath condensate. Eur Respir J 2006; 28: 1036-1041.

5 Gaber F, Acevedo F, Delin I, et al. Saliva is one likely source of leukotriene B4 in exhaled breath condensate. Eur Respir J 2006; 28: 1229-1235.

6 Clary-Meinesz C, Mouroux J, Cosson J, Huitorel P, Blaire B. Influence of external $\mathrm{pH}$ on ciliary beat frequency in human bronchi and bronchioles. Eur Respir J 1998; 11: 330-333.

7 D'Amato G, Liccardi G, Frenguelli G. Thunderstorm-asthma and pollen allergy. Allergy 2007; 62: 11-16.

8 Chen $\mathrm{CH}$, Xirasagar S, Lin CH. Seasonality in adult asthma admissions, air pollutant levels, and climate: a populationbased study. J Asthma 2006; 43: 287-292.

9 Burge PS. Prevention of exacerbations: how are we doing and can we do better? Proc Am Thorac Soc 2006; 3: 257-263.

DOI: $10.1183 / 09031936.00128007$

\section{Isolated diastolic dysfunction of right ventricle: stress-induced pulmonary hypertension}

\section{To the Editors:}

We read with great interest the article of HuEz et al. [1]. Their results, which were mostly noninvasive, suggest that isolated longitudinal diastolic dysfunction of the right ventricle may be a sign of stress-induced (or latent) pulmonary hypertension. The aim of our letter is to confirm this observation with the help of our results based on invasive measurements.

In total, 58 patients (mean age $54 \pm 8$ yrs, 48 female) were examined. These comprised 15 healthy subjects who had no signs or symptoms of heart disease and 43 consecutive patients suffering from connective tissue disease (CTD), of whom 38 had systemic sclerosis, two had systemic lupus erythematosus, two had mixed CTD and one had polymyositis. Patients in the latter group were referred to the University of Pécs (Pécs, Hungary) on suspicion of pulmonary artery hypertension $(\mathrm{PAH})$. Patients with atrial fibrillation and severe mitral or tricuspid insufficiency were excluded from the study.

The local ethics committee approved the study. All subjects had given written informed consent prior to undergoing echocardiography and right heart catheterisation.

Echocardiography was performed using an Aloka ProSound 5500 ultrasound system (Aloka Co. Ltd, Tokyo, Japan). Left ventricular ejection fraction was measured by Simpson's method. Right ventricular end-diastolic diameter was obtained from standard parasternal long axis view using M-mode measurements. Transmitral flow was recorded from the apical four-chamber view. The peak of the early (E) diastolic velocities was measured. Systolic pulmonary artery pressure (PAP) was estimated as a sum of the pressure difference across the tricuspid valve calculated using the modified Bernoulli equation and an estimate of mean right atrial pressure. Myocardial systolic, early $\left(E^{\prime}\right)$ and late diastolic velocities were measured from apical four-chamber view at the lateral border of the mitral and tricuspid annulus using tissue Doppler imaging. The mitral E/E' ratio was calculated. Doppler measurements were obtained from at least three consecutive beats during end-expiratory apnoea.

All patients with CTD underwent right heart catheterisation. A Swan-Ganz catheter was introduced to a main pulmonary artery branch. If the resting mean PAP $(P$ pa $)$ was $<30 \mathrm{mmHg}$, a 3 min bench-fly physical stress test was performed using two $1-\mathrm{kg}$ dumbbells. $P$ pa was measured at rest and at peak exercise.

Differences between groups were tested for significance using ANOVA. Post hoc tests were performed by Scheffe's method. Comparisons of nonparametric data were performed using Chisquared tests. A p-value of $<0.05$ was considered significant.

Thirteen patients belonging to the CTD group had resting $(P$ pa: $37.9 \pm 10.9 \mathrm{mmHg}$ ) PAH diagnosed by right heart catheterisation. In six patients, normal PAP values were measured at rest $(22.8 \pm 1.7 \mathrm{mmHg})$ while elevated values were measured at peak exertion $(39.8 \pm 6.3 \mathrm{mmHg})$.

Considering these results, the CTD patients were divided into the following three groups: 24 patients without $\mathrm{PAH}$, six patients with stress-induced $\mathrm{PAH}$ and 13 patients with resting 